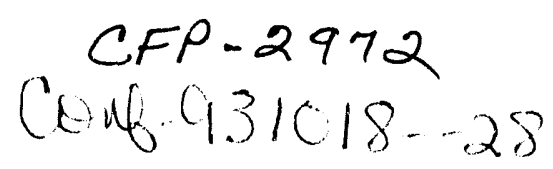

\title{
DEVELOPMENT and IMPLEMENTATION OF THE TPX STRUCTURAL and CRYOGENIC DESIGN CRITERIA
}

\author{
I. Zatz, P. Heitzenroeder (PPPL) \\ Princeton Plasma Physics Laboratory \\ US Route 1-North, Box 451, Princeton, New Jersey 08543
}

J.H. Schultz (MIT)

MIT Plasma Fusion Center

167 Albany St., Cambridge, MA 02139

\begin{abstract}
The Tokamak Physics Experiment (TPX) is a superconducting tokamak utilizing both $\mathrm{Nb}_{3} \mathrm{Sn}$ and $\mathrm{NbTi}$ superconducting magnets and will feature a low-activation titanium alloy vacuum vessel and carbon-carbon composite divertors. Due to the unique nature of the component designs, materials, and environment, the TPX project felt it necessary to develop a design criteria (code) which will specifically address the structural and cryogenic design aspects of such a device. The developed code [Ref. 1] is intended to serve all components of the device; namely, the TF and PF magnets, vacuum vessel, first wall and divertor, cryostat, diagnostics, heating devices, shielding, and all associated structural elements. The structural portion is based largely on that developed for the Burning Plasma Experiment (BPX) [Ref. 2], which was modeled after the CIT Vacuum Vessel Structural Design Criteria [Ref. 3] and ASME Boiler and Pressure Vessel (B\& PV) Code [Ref. 4]. The cryogenic criteria is largely modeled after that proposed in the ITER CDA [Ref. 5]. This paper summarizes the TPX Criteria document.
\end{abstract}

\section{INTRODUCTION}

The TPX Criteria evolved through a series of meetings and discussions involving a broad range of participants from both within and outside the fusion community. Early in the process it became obvious that no existing code or combination of existing codes can fully address the needs of a tokamak. A tokamak, especially a superconducting tokamak, presents environmental, loading, and materials challenges which are significantly different than, for example, a pressure vessel. Furthermore, no code addresses the design of superconductors. Consequently, it was clear that the cryogenic portion had to be written without the benefit of an applicable pre-existing criteria model. It was felt that in the structural area much could be gained from the existing codes. The aerospace approach was considered and rejected because of its "incremental" approach to introducing new materials and design criteria and its requirement of a large, historical data base to support it. The $\triangle$ SME B\&PV Code was ultimately chosen as the most applicable model on which to base the TPX Criteria. The developed TPX Structural Criteria section follows the intent of the Code, but incorporates significant differences. Key differences include the consideration of loads and load combinations unique to tokamaks, the use of higher static allowables for materials where $\mathrm{U}_{\text {. }}$ ultimate stress dominates, unique treatment of electrical insulatus as primary structural materials, introduction of fracture mechanics into the fatigue design process, and permitting the use of any structural material which consistently demonstrates adequate mechanical properties.

\section{STRUCTURAL CRITERIA}

\section{Design Loads}

The following design loads are considered in various combinations prescribed in the Criteria:

Dead loads $(D)$ : primarily the weight of the component and attached elements.

Design Pressure $(P)$ : the pressure imposed on a component due to hydraulic or gas pressures in a worst-case fault scenario.

Normal Operating Thermal Effect (To): loads imposed by temperature changes before, during, and after a pulse.

Electromagnetic Loads (EM): loads on magnets due to the currents flowing in the conductors interacting with the magnetic fields crossing them. These loads also include electromagnetic effects of discharge cleaning.

Electromagnetic Loads During Faults (EM-F): Electromagnetic loads induced during abnormal events such as control failures, power supply failures, bus faults, etc.

Interaction Loads (IR): Loads superimposed by interactions between components; for example, the load due to a PF coil supported on the TF coil.

Electromagnetic Loads Due to Plasma Disruption (EM-D): The electromagnetic loads induced during a plasma disruption.

Seismic Loads: Loads induced by the Safe Shutdown Earthquake (SSE) or Most Intense Earthquake (MIE) as specified in the TPX General Criteria Document. [Ref. 6].

\section{Load Combinations}

TPX components shall be designed for both normal operating conditions and off-normal events. The load combinations are defined below $(P=$ the estimated probability of occurrence per year):

Normal Operating Events (Normal) $(P \leq 1)$

$\mathrm{D}+\mathrm{P}$ (where applicable $)+\mathrm{T} \mathrm{O}+\mathrm{EM}+\mathrm{IR}$

$\mathrm{D}+\mathrm{P}$ (where applicable) $+\mathrm{T}_{\mathrm{O}}+(\mathrm{EM}-\mathrm{D})+\mathbb{R}$

Anticipated Events (Upset) $\left(1 \geq P>10^{-2}\right)$

$\mathrm{D}+\mathrm{P}$ (where applicable $)+\mathrm{T}_{\mathrm{O}}+(\mathrm{EM}-\mathrm{F})+\mathrm{IR}$

Unlikely Events (Severe Accident Emergency)

$\left(10^{-2} \geq P \geq 10^{-4}\right)$

$D+P($ where applicable $)+T_{O}+F_{S S E}+I R$

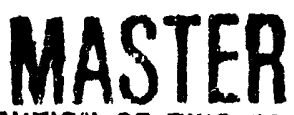

DISTRIBUTION OF THIS DOCUMENT IS UNLIMITEO 
Extremely Unlikely (Faulted) $\left(10^{-4} \geq P \geq 10^{-6}\right)$

$\mathrm{D}+\mathrm{P}$ (where applicable) $+\mathrm{T}_{\mathrm{O}}+\mathrm{EM}+\mathrm{IR}+\mathrm{F}_{\mathrm{SSE}}$

$\mathrm{D}+\mathrm{P}$ (where applicable $)+\mathrm{T}_{\mathrm{O}}+(\mathrm{EM}-\mathrm{D})+\mathrm{IR}+\mathrm{F}_{\mathrm{SSE}}$

Incredible Events $\left(P<10^{-6}\right)$

Loads related to these events do not require consideration.

\section{Stress Categories}

Three categories of stress are considered:

(1): Primary Stress: A stress developed by the imposed loading which is necessary to satisfy the laws of equilibrium. There are three sub-categories of primary stress:

a) General primary membrane stress ( $(\mathrm{PM})$ ); example, the skin of a sphere under pressure;

b) Local primary membrane stress ( $\left.P_{L}\right)$; example, a nonspherical head;

c) Primary Bending Stress $(\mathrm{Pb})$; example, a loaded beam.

(2) Secondary Stress, $Q$ : A stress developed by the constraint of the adjacent material or by self-constraint of the structure.

(3) Peak Stress, F: An increment of stress which is additive to the primary plus secondary stress due to local discontinuity or local thermal stress.

The stress limits are based on Tresca stress, $S_{m}$, defined as twice the maximum shear stress (i.e. the largest algebraic difference between any two of the three principal stresses). This is equivalent to the stress intensity referred to in the ASME Boiler and Pressure Code.

\section{STRESS LIMITS}

For Non-Superconducting Conductor Materials: $\mathrm{S}_{\mathrm{m}}$ shall be based on $2 / 3$ of the minimum yield strength at temperature for materials where sufficient ductility is demonstrated.

For support structures and other steel structures, $\mathrm{S}_{\mathrm{m}}$ shall be the lesser of $2 / 3$ of the minimum specified yield at temperature or $1 / 2$ of the minimum specified tensile strength at temperature.

For materials which are neither conductor nor steel, $S_{m}$ shall be the lesser of $2 / 3$ of the minimum specified yield at temperature, with strength and ductility requirements to be established for each specific material.

For bolting materials, $\mathrm{S}_{\mathrm{m}}$ shall be less than $2 / 3$ of the minimum specified yield at every point in time.

For welds in steel, $\mathrm{S}_{\mathrm{m}}$ shall be the lesser of $2 / 3$ of the minimum specified yield at temperature or $1 / 3$ of the minimum specified tensile strength at temperature. This Criteria considers the weld to include the weld metal, heat affected zone, and base metal interface.

For welds in materials other than steel, $S_{m}$ shall be $2 / 3$ of the minimum specified yield of tie weld at temperature and it must meet ductility requirements to be established for each type of weld independently.

Since weld properties are very strongly a function of the weld metallurgy and technique, the strength properties shall be the minimum of the values resulting from a test lot of at least 6 specimens. The analysis must consider residual stresses due to differential cool-down contractions.

Basic Stress Limits:

Based on elastic stress analyses, the following stress limits shall be met:
- General primary membrane stress shall not exceed 1.0 $\mathrm{KS}_{\mathrm{m}}$.

- Local primary membrane stress shall not exceed $1.5 \mathrm{KS}_{\mathrm{m}}$.

- Primary membrane plus bending stresses shall not exceed

$1.5 \mathrm{KS}_{\mathrm{m}}$.

- Total primary plus secondary stress shall not exceed 3.0 $\mathrm{KS}_{\mathbf{m} \text {. }}$

- The multiplier $K$ is dependent on the level of service conditions, as discussed below.

\section{K Factors}

The appropriate $K$ values for various load combination categories are:

- For normal operating conditions, $K=1.0$.

- For upset conditions, $\mathrm{K}=1.1$.

- For emergency conditions, $\mathrm{K}=1.2$; evaluation of secondary stress not required.

- For faulted conditions, $\mathrm{K}=1.35$; evaluation of secondary stress not required.

\section{Stress Limits for Bolting Material}

For preload: Bolt preload stress shall not exceed the lesser of 0.75 the yield stress, $S_{y}$, at room temperature or $0.75 S_{y}$ at operating temperature.

For operating loads: Average tensile stress due to primary loads shall not exceed $1.0 \mathrm{~S}_{\mathrm{m}}$. The maximum direct tension plus bending stress due to primary loads shall not exceed 1.5 $\mathrm{s}_{\mathrm{m}}$.

For preload combined with operation: At any point in time, combined operating loads and preload sha:! be evaluated for compatibility with joint design but in any case the maximum shall not exceed $0.9 \mathrm{~S}$.

\section{Stress Limits for Insulating Materials}

Compressive Stress Allowables: The design allowable flatwise compressive stress of continuous sheets of insulating material shall be limited by $2 / 3$ of the ultimate stress at temperature. In addition, the material shall be tested to show 5 times the required life with compressive fatigue tests using the maximum compressive stress, or, when shear is present, the worst case combination of compression and shear, using a representative test specimen configuration(s).

Shear Stress Allowables: The shear stress allowable for an insulating material is most strongly a function of the particular material and processing method chosen, the stress loading conditions, and the radiation exposure level. Experimental tests indicate that the total shear load capability of a material under compressive loads is the sum of the intrinsic shear capability of the material plus the coefficient of friction times the compressive stress. This is expressed in the following formula, which is used for initial quantification of the allowable shear with a safety factor of $2 / 3$ applied:

Where:

$$
S_{S}=2 / 3\left(t_{0}+C_{2} * S_{n}\right)
$$

$t_{0}=$ the experimentally determined intrinsic shear bond strength of the material with no compressive load at the temperature and radiation level representative of the service condition. This value is to be the minimum value from a sample lot of at least 6 specimens. For the sample 
lot to be valid, the process is to be developed such that the scatter of values shall not exceed $+/-10 \%$ from the mean value.

$\mathrm{C}_{2}=$ an experimentally determined factor for the proposed insulating material based on combined shear and compression testing.

$S_{n}=$ the local normal compressive stress.

Verification by Testing:

The shear allowable must, in all cases, be verified by testing of irradiated test specimens of the materials selected. Adequate fatigue life must be demonstrated for five times the design life with combined shear and c ompression loading. In cases where slippage is expected to occur, laboratory tests of the suitability of the wear characteristics of the chosen materials for at least five times the design life must be made, using representative test specimen configuration(s).

\section{FATIGUE EVALUATION}

Two alternative approaches are permitted:

(1) The traditional ASME B\& PV Code-oriented Fatigue Evaluation; or

(2) an approach based on equivalent uniaxial stress.

In both approaches, the effect of mean stress and damage accumulation must be included in the analyses.

\section{Design S-N Fatigue Curves}

The S-N fatigue curves shall be obtained based on uniaxial strain cycling tests at given temperatures (service temperatures) and at various $\mathrm{R}$ ratios. $\mathrm{S}-\mathrm{N}$ fatigue curves shall be developed for both the base metal and for weld regiors.

The design S-N fatigue curve shall be obtained by applying a factor of 2 on stress or a factor of 20 on cycles, whichever is more conservative, to the best fit curve to the data.

\section{Crack Growth Limitations}

Fracture mechanics analyses shall be performed to quantify the maximum permissible initial flaw size for both the base metal and weld region. The maximum permissible initial flaw size shall be governed by, as a minimum, two times the growth life experimentally determined based on component tests, or four times the growth life experimentally determined based on material tests. A minimum of 3 component samples or 6 material samples shall be used in the experimental determination. Certain materials or orientations may require additional specimens over and above these criteria, if the scatter of the data is deemed significant.

\section{SUPERCONDUCTING MAGNET DESIGN CRITERIA}

\section{Protection Criteria}

Maximum Quench Voliage, defined as the product of the peak operating current times the durnp resistance, shall be no higher than $15 \mathrm{kV}$ at the coil terminals. This assumes that the terminals are balanced with respect to ground which results in the terminal to ground voltage limited to $7.5 \mathrm{kV}$.

Quench pressure rise is the pressure rise due to the local hot spot in a quench flashing the liquid helium to gaseous helium.
It is permissible to account for helium expulsion at the inlets and outlets. The conduit stresses in such an event must meet the requirements set forth in the structural criteria section.

Maximum Quench Temperature is the worst local peak winding pack temperature during a quench at any time point in a normal scenario, and shall be limited to no higher than $150 \mathrm{~K}$.

Quench Instrumentation and Diagnostics may include any or all of the following:

- voltage taps to detect unbalanced voltages in similar coils or pancakes;

- co-wound wire voltage detectors in a bridge circuit

with an individual pancake;

- co-wound fiber optic temperature sensor to detect unpredicted ternperature rises;

- pressure sensors at the inlet and outlet to detect

unpredicted pressure rises;

- detection of flow reversal at the helium inlet.

It is required that the quench detection system be capable of detecting a failure in any section of any coil to recover from a normal event and initiate a quench dump within 1 second of the beginning of that event. At least two independent methods must be employed.

\section{Cryogenic Criteria}

Temperature margin is the minimum difference between the local current-sharing temperature and the actual local helium temperature during a complete scenario, and shall be at least 1 ${ }^{\circ} \mathrm{K}$.

Temperature headroom is the difference between the minimum local current-sharing temperature in a magnet during a complete scenario and the helium inlet temperature, and shall be a minimum of $2^{\circ} \mathrm{K}$.

Energy headroom is the minimum local difference between the energy deposited in the cable volume needed to raise the local helium at constant density to the current-sharing temperature of the superconductor, beginning at the inlet temperature of the helium. The minimum energy headroom shall be $600 \mathrm{~mJ} / \mathrm{cc}$.

Energy margin is the minimum local difference between the energy deposited in the cable volume needed to raise the local helium to the current-sharing temperature of the superconductor, beginning at the actual local temperature of the helium and superconductor. The minimum energy margin shall be $300 \mathrm{~mJ} / \mathrm{cc}$.

Safety factor is the minimum ratio of the predicted local energy deposition to the energy headroom during a scenario, and shall be at least 2 .

Fraction of critical current is the ratio of the operating current in a magnet to the minimum local value of critical current in the full cable as a function of time, field, temperature, and strain during a scenario. The fraction of critical current shall be limited to less than 0.6 for a normal scenario and less than 0.8 for a scenario terminating in a disruption.

Critical current at any given field, temperature, and strain is defined as the operating current at which there is an electric field in the conductor of $0.1 \mu \mathrm{V} / \mathrm{cm}$.

Residual resistivity ratio, or $R R R$, is the ratio of the matrix resistivity at $293 \mathrm{~K}$ and zero field to the resistivity at the critical temperature and zero field. The RRR of a $\mathrm{Nb}_{3} \mathrm{Sn}$ composite conductor matrix cannot be assumed to be higher 
than 75 for design purposes, or higher than 150 for a $\mathrm{NbTi}$ composite conductor matrix.

Copper fraction, $f_{C u}$, is the volume fraction of highconductivity copper in a composite superconductor. The fraction of copper in bronze is not included in this calculation. Presently, manufacturing limitations result in $0.1<\mathrm{f}_{\mathrm{Cu}}<0.55$ in a single-barrier internal tin composite wire; and 0.2 $<\mathrm{f}_{\mathrm{Cu}}<0.67$ for a modified jelly roll.

Cable twist pitch affects both the mechanical stiffness of a cable and the coupling and eddy current losscs. It is required that all strands and subcables be twisted with the same handiness, and that an appropriate balance be reached between the magnetic, mechanical, and practical manufacturing considerations.

Recovery power balance requires that the equations below be met:

$$
Q^{\prime \prime \prime} A_{\text {metal }}[W / m]<800\left[W / m^{2}-K\right] P_{w}\left(T_{c s}-T_{b}\right)
$$

$$
J_{C w}^{2} \rho_{C u} A_{C_{u}}[W / m]<1400\left[W / m^{2}-K\right] P_{w}\left(T_{c}-T_{b}\right)
$$

The special constraint on the mean heat transfer coefficient or hybrid cables can be restated as:

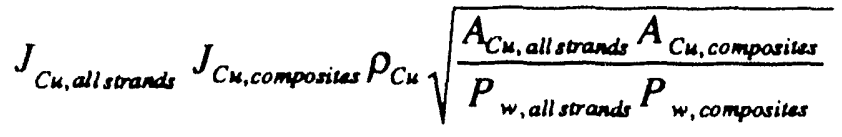$$
<1400\left(T_{c}-T_{b}\right)
$$

where $\mathrm{J}_{\mathrm{Cu}}$ is the current density in the copper on quench $\left(\mathrm{A} / \mathrm{m}^{2}\right), \mathrm{T}_{\mathrm{C}}$ is the critical temperature $(\mathrm{K}), \mathrm{T}_{\mathrm{CS}}$ is the current sharing temperature of the superconductor, $P_{W}$ is the wetted perimeter of the cable (m), $\mathrm{ACu}$ is the copper cross-sectional area of a cable $\left(\mathrm{m}^{2}\right)$, and ${ }^{\circ \mathrm{Cu}}$ is the resistivity of the copper $(\Omega-\mathrm{m})$.

Irreversible strain is the strain beyond which $\mathrm{Nb}_{3} \mathrm{Sn}$ will fail to recover its original properties when returned to zero intrinsic strain. At all times after the formation of $\mathrm{Nb}_{3} \mathrm{Sn}$ the strain in the superconductor shall be less than 0.75 of the irreversible strain.

Effective strain is defined as the longitudinal strain in the superconductor that gives the same degradation in critical properties as the actual combined strain. The effect of longitudinal strain on critical properties shall follow Ekins' rules [Ref. 7]. Determination of the effective strain state in the superconductor must be calculated and subject to peer review.

Neutron fluence shall be limited to an integrated value of $<1$ $x 10^{23} \mathrm{n} / \mathrm{m}^{2}$ of neutrons with energies $>0.1 \mathrm{MeV}$.

Copper damage shall be limited to $<5 \times 10^{-4} \mathrm{dpa}$, corresponding to an approximate rise in the unannealed copper resistivity of $7.4 \times 10^{-10} \Omega$-m [Ref. 8 ].

Insulator radiation dose deposited locally over a conductor width by nuclear irradiation shall be less than $5 \times 10^{7} \mathrm{~Gy}$. The average energy deposited in the insulation over a broad region should be less than $2 \times 10^{7} \mathrm{~Gy}$.

Conductor joints : The normal conducting region in a joint may not propagate into the superconducting winding under either steady-state or pulsed loss conditions. If the joint is cooled by liquid helium, power balance of peak joint losses into the coolant must not exceed $5,000 \mathrm{~W} / \mathrm{m}^{2}-\mathrm{K}$. If the joint is cooled by supercritical helium, power balance of peak joint losses must not exceed $600 \mathrm{~W} / \mathrm{m}^{2}-\mathrm{K}$. All other constraiats applying to the rest of the conductor and insulation design are also applied to joints.

Insulation voltage stress may not exceed $2.5 \mathrm{kV} / \mathrm{mm}$ for glass-epoxy insulation and $8 \mathrm{kV} / \mathrm{mm}$ for multiple high dielectric strength tapes such as Kapton. The total thickness of any insulator or series of insulators must be $>0.5 \mathrm{~mm}$ to avoid punctures due to impurities.

Vacuum breakdown voltage is defined as the sphere to sphere voltage that will arc at the design pressure of the external cryostat of $0.1 \mathrm{~Pa}$. To avoid this condition, no exposed metal surfaces at different potentials are permitted.

Helium breakdown voltage is the sphere to sphere voltage that will arc at a given distance, temperature, and pressure in helium, independent of surface effects. The design value shall be ten times less than that calculated for helium breakdown.

Flashover is defined as a dielectric breakdown across the surface of an insulator. The flashover electric field shall be limited to one-half of the breakdown field in helium at the same temperature and pressure.

Tracking along an insulator surface is the gradual creation of a conducing path along the surface of an organic insulator through carbonization. The maximum field along the surface shall be $>80 \mathrm{~V} / \mathrm{mm}$ to avoid tracking.

\section{REFERENCES}

[1] P. Heitzenroeder, Editor; "TPX Structural and Cryogenic Design Criteria; Doc. \# 94-921012-PPPL/PHeitzenroeder-01; September, 1992.

[2] P. Heitzenroeder, Editor; "BPX Magnet Structural Design Criteria"; Doc. \# F-910208-PPL-03, Rev. 0, February 1991 .

[3] S.J. Chen;"CIT Vacuum Vessel Structural Design Criteria"; Report D-890712-PPL-03 TR-03, Rev. R0, July 1989.

[4] ASME, "1986 ASME Boiler and Pressure Vessel Code", July 1986.

[5] ITER Documentation Series No. 26: "ITER Magnets"; International Atomic Energy Agency; Vienna; 1991.

[6] W. Reiersen, Editor; "TPX General Requirements Document" ; Doc. \# 91-930319-PPPL/WReiersen-01.

[7] J. W. Ekin, "Strain scaling law for flux pinning in practical superconductors. Part 1: Basic relationship and application to $\mathrm{Nb}_{3} \mathrm{Sn}$ conductors," Cryogenics, V. 20(11), p. 611, Nov., 1980.

[8] M. Soell, "Influence of radiation damage on the maximum attainable magnetic field for a tokarnak reactor," $J$. Nuc. Matls 72 (1978), 168.

\section{ACKNOWLEDGMENTS}

This criteria is the result of the combined efforts of people throughout the world fusion community. We especially want to extend our thanks to S.J. Chen of Ebasco; H. Becker and J. Minervini of MIT; G. Cargulia and J. Citrolo of PPPL; J. Miller of the National High Magnetic Field Laboratory; J. Ekin of NIST; and W. Hassenzahl of LLNL.

This work was supported by the US Department of Energy under Contract No. DE-AC02-76-CH03073. 


\section{DISCLAIMER}

This report was prepared as an account of work sponsored by an agency of the United States Government. Neither the United States Government nor any agency thereof, nor any of their employees, makes any warranty, express or implied, or assumes any legal liability or responsibility for the accuracy, completeness, or usefulness of any information, apparatus, product, or process disclosed, or represents that its use would not infringe privately owned rights. Reference herein to any specific commercial product, process, or service by trade name, trademark, manufacturer, or otherwise does not necessarily constitute or imply its endorsement, recommendation, or favoring by the United States Government or any agency thereof. The views and opinions of authors expressed herein do not necessarily state or reflect those of the United States Government or any agency thereof. 


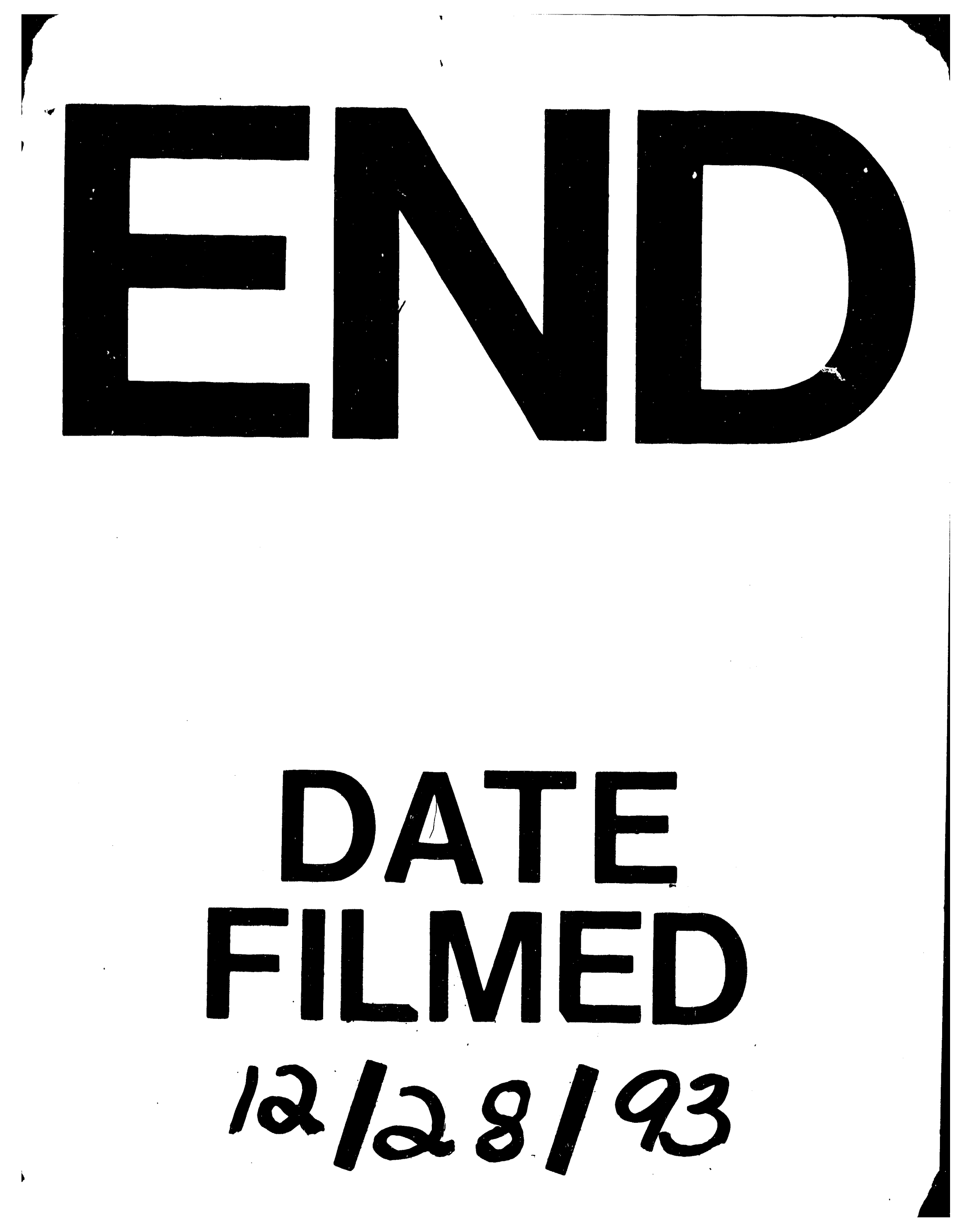


